\title{
Mechanical Properties of Wood Flour Reinforced High Density Polyethylene Composites with Basalt Fibers
}

\author{
Guojun LU ${ }^{1}$, Weihong WANG ${ }^{1 *}$, Shijie SHEN ${ }^{2}$ \\ ${ }^{1}$ Key Laboratory of Bio-based Material Science \& Technology of Ministry of Education, \\ Northeast Forestry University, 150040 ,26\# Hexing Road, Harbin, China \\ ${ }^{2}$ Beijing Forestry University, 100083, 35\# Tsinghua east road, Beijing, China \\ crossref http://dx.doi.org/10.5755/j01.ms.20.4.6441
}

Received 13 February 2014; accepted 10 September 2014

\begin{abstract}
Basalt fibers (BFs) were surface-treated with a vinyl triethoxy silane coupling agent to improve the mechanical properties of wood fiber-reinforced high density polyethylene (HDPE) composites. Basalt fibers were characterized with SEM and FT-IR. The effects of the basalt fiber content and apparent morphology on the mechanical properties of the hybrid composites were investigated in this paper. The results show that the BF coated with the vinyl triethoxy silane coupling agent resulted in an improvement in mechanical properties due to the increased interfacial compatibility between the BF and HDPE. The flexural strength and impact properties significantly increased with 4 wt. $\%$ modified basalt fibers.

Keywords: Basalt fiber, surface modification, WF/HDPE plastic composites, mechanical properties.
\end{abstract}

\section{INTRODUCTION}

In recent years, there has been an increased interest in developing composite materials from renewable resources. Wood fiber-reinforced thermo-plastics, usually called wood plastic composites (WPCs), have recently received a great deal of attention from both academia and industry [1-4]. The mechanical properties, color and texture of WPCs are similar to that of wood, and hence WPCs are widely used in gardening, municipal applications, automobiles, and other applications such as pallet construction $[5,6]$. Waste plastic and wood sources can be used as raw materials to manufacture WPCs, resulting in "turning waste into something useful" [ 7, 8].

However, the mechanical properties of WPCs are insufficient to fit the requirements of structural and engineering construction. The reason is that the hydrophilic bio-fibers and hydrophobic thermoplastic matrix usually creates a weak interfacial bond between $[9,10,19]$. In this case, high performance fibers were investigated to improve the WPCs' properties.

Basalt fibers (BFs) are made from volcanic rocks. It has been tried to use $\mathrm{BF}$ as an alternative reinforcement material for polymer matrix composites [11, 12]. Their chemical compositions are similar to that of glass, and its basic components are $\mathrm{Al}_{2} \mathrm{O}_{3}, \mathrm{SiO}_{2}, \mathrm{CaO}, \mathrm{MgO}, \mathrm{K}_{2} \mathrm{O}, \mathrm{Na}_{2} \mathrm{O}$, $\mathrm{Fe}_{2} \mathrm{O}_{3}$ and $\mathrm{FeO}$ [13]. In recent years, basalt fibers have been studied extensively as reinforcements in both thermoplastic and thermosetting matrices [14-16], however, their applications in wood plastic composites have rarely been reported. In a previous investigation, basalt fibers ranging in length from $3 \mathrm{~mm}$ to $12 \mathrm{~mm}$ were directly added into a commercial WPC that had been characterized [17], and the addition of BF did not lead to

\footnotetext{
${ }^{*}$ Corresponding author. Tel.: +86045182191552, fax: +86045182190931. E-mail address: weihongwang2001@aliyun.com (W. Wang)
}

an important improvement in the tensile and flexural strength of the WPC. The purpose of present research was to evaluate the influence of the added modified basalt fibers into wood fiber/high density polyethylene (WF/HDPE) composite on the mechanical properties of the hybrid-reinforced plastic composites.

\section{EXPERIMENTAL}

\subsection{Materials}

HDPE (5000S resin, density $0.954 \mathrm{~g} \cdot \mathrm{cm}^{-3}$, melt flow index $\left.0.7 \mathrm{~g} \cdot 10 \mathrm{~min}^{-1}\right)$ was purchased from Daqing Petrochemical Co. Ltd. China, and was used as a matrix in this research. The Basalt fibers $(6 \mathrm{~mm}$ in length, $17 \mu \mathrm{m}$ in diameter) were provided by Zhejiang GBF Basalt Fiber Co. Ltd. China. Wood fibers (40-mesh to 80-mesh) were bought from Harbin Yongxu Company, China. Vinyl triethoxy silane coupling agent (YGO-1203) was obtained from Harbin Chemical Research Institutes, China.

\subsection{Samples preparation}

\subsubsection{Surface treatment of BF}

Basalt fibers were extracted from a Soxhlet extraction apparatus after being soaked in acetone for $12 \mathrm{~h}$, and then washed with deionized water for $3 \mathrm{~h}$ to remove any impurities. These treated basalt fibers were dried in an oven at $110^{\circ} \mathrm{C}$ for $3 \mathrm{~h}$, and then were cooled to room temperature.

The mixed solvent was prepared by mixing $90 \%$ anhydrous ethanol and $10 \%$ distilled water at room temperature, then vinyl triethoxy silane coupling agent was added to this mixed solvent. The $\mathrm{pH}$ value was buffered to about 3.5 by adding glacial acetic acid and stirring for 5 min. BFs were submerged in the mixed solvent for $30 \mathrm{~min}$ and then filtered from the solution. The BF fibers were dried at room temperature before the grafting reaction 
was carried out at $120^{\circ} \mathrm{C}$ for $2 \mathrm{~h}$. Then the treated fibers were washed alternately with deionized water and acetone.

\subsubsection{Preparation of composite sample}

Wood fibers were dried in a drying oven at $105^{\circ} \mathrm{C}$ to reduce moisture content to less than $3 \%$. HDPE, BF (Original or Modified), and WF were mixed in a high-speed mixer for $10 \mathrm{~min}$, and then were transferred to a twin-screw/single-screw extruder system to directly produce $\mathrm{BF} / \mathrm{WF} / \mathrm{HDPE}$ composite lumber. The specific ratio of HDPE, BF, and WF are listed in Table 1.

Table 1. Hybrid composites and their compositions

\begin{tabular}{|c|c|c|c|}
\hline Composites & $\begin{array}{c}\text { HDPE, } \\
\text { wt.\% }\end{array}$ & $\begin{array}{c}\text { WF, } \\
\text { wt.\% }\end{array}$ & $\begin{array}{c}\text { Modified BF, } \\
\text { wt.\% }\end{array}$ \\
\hline WPC & 36 & 60 & 0 \\
\hline YWPC-4 & 36 & 56 & 4 \\
\hline YWPC-8 & 36 & 52 & 8 \\
\hline YWPC-12 & 36 & 48 & 12 \\
\hline
\end{tabular}

\subsection{Characterization}

\subsubsection{Fourier transform infrared spectroscopy (FT-IR) analysis}

The original and modified BF was analyzed with FT-IR in a Magna-IR 560 (Thermo Nicolet) at room temperature to investigate the formation of the chemical bonding while considering the surface treatment of the basalt fiber. Data were collected from $400 \mathrm{~cm}^{-1}$ to $4000 \mathrm{~cm}^{-1}$ with 32 scans for each sample.

\subsubsection{Mechanical tests}

Tensile properties were evaluated with a crosshead speed of $5 \mathrm{~mm} / \mathrm{min}$, and flat tensile specimens with $(50 \times 13 \times 4) \mathrm{mm}$ gauge dimensions were machined according to ASTM D638-2004.

Three-point flexural tests with $(80 \times 13 \times 4) \mathrm{mm}$ specimens were carried out according to ASTM D790-2004. A crosshead speed of $2 \mathrm{~mm} / \mathrm{min}$ and span length of $64 \mathrm{~mm}$ were used for testing.

The unnotched Izod impact strength of the composites was determined from similar tests with $(63.5 \times 12.7 \times 4) \mathrm{mm}$ specimens according to ASTM D256-2006.

Each test was repeated at least six times, and the average value was calculated.

\subsubsection{Scanning electron microscopy (SEM)}

Interfacial bonding in the BF/WF/HDPE composite was investigated with SEM. Samples were first frozen in liquid nitrogen and then broken. The fracture surfaces were subsequently sputter-coated with gold. The observation was conducted with a FEI QuanTa200 SEM (Holland). The accelerating voltage was $12.5 \mathrm{kV}$.

\section{RESULTS AND DISCUSSION}

\subsection{FT-IR spectroscopy}

Basalt fibers were treated with silane agent coupling to improve their bonding with the HDPE matrix.
The FT-IR spectra of the BF both treated and untreated with the silicane coupling agent are shown in Fig. 1. Compared with the untreated $\mathrm{BF}$, new peaks appeared at $2869 \mathrm{~cm}^{-1}, 1733 \mathrm{~cm}^{-1}, 1510 \mathrm{~cm}^{-1}$, and $1372 \mathrm{~cm}^{-1}$ in the spectra of the treated BF (Fig. 1, b). These peaks correspond to alkane $\left(2869 \mathrm{~cm}^{-1}\right),-\mathrm{CH}_{2}-\left(1510 \mathrm{~cm}^{-1}\right)$, and $-\mathrm{CH}_{3}\left(1372 \mathrm{~cm}^{-1}\right)$, which were introduced by the silicane coupling agent. In this research, the hydrogen bonding occurred between basalt fiber and hydrolyzed coupling agent, which leads to a flexible coupling agent layer formed at the surface of basalt fiber and crosslinking with polyethylene substrates [18]. As a result, the interfacial adhesion between the BF and HDPE matrix was strengthened. The FT-IR spectra indicated that the surface of the BF was coated with the coupling agent layer.

However, new peak of $1733 \mathrm{~cm}^{-1}$ was not related to basalt fiber and coupling agent, it was probably the vestigial glacial acetic acid which was used to buffer $\mathrm{pH}$ value at 2.2.1. Some researchers presumed that the silicane coupling agent easily reacts with the $-\mathrm{OH}$ groups on the surface of the BF [18], however, we did not find the peak of the reactive product, $\mathrm{Si}-\mathrm{O}-\mathrm{Si}$, at around $1100 \mathrm{~cm}^{-1}$.

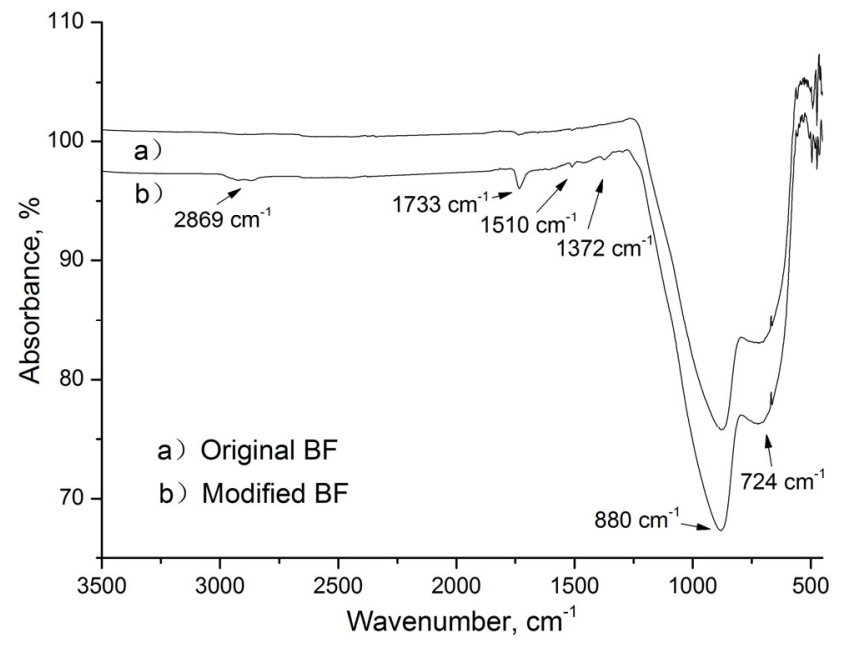

Fig. 1. FTIR spectra of BF: $a-$ original BF, $b-B F$ modified with Vinyl triethoxy silane coupling agent

\subsection{Mechanical properties of the composites}

The tensile properties of the WF/BF/HDPE composites are shown in Fig. 2. Compared with the composites that did not contain $\mathrm{BF}$, the tensile strength and tensile modulus of the composites containing $4 \mathrm{wt} . \%$ treated BF (YWPC) increased by $9.1 \%$ and $9.7 \%$, respectively (Fig. 2, a). However, the tensile strength and tensile modulus did not change much with further increases in the basalt fiber content.

With respect to the flexural property, the addition of $4 \mathrm{wt} . \%$ modified BF resulted in an increase in flexural strength by up to $14.0 \%$ and flexural modulus by $3.4 \%$ (Fig. 2, b). When the content of modified BF was further raised to $12 \mathrm{wt} . \%$, the flexural strength and modulus increased by $17.1 \%$ and $10.4 \%$, respectively.

The unnotched impact strength of the composite was also improved by adding BF (Fig. 2, c). When the BF contents were $4 \mathrm{wt} . \%, 8 \mathrm{wt} . \%$ and $12 \mathrm{wt} . \%$, the increases in the impact strength were $28.2 \%, 39.4 \%$, and $42.4 \%$, respectively. Generally speaking, the addition of basalt 
fibers to the composite improved its impact strength due to reduction of the stress concentration. In the present research, this improvement may be also attributed to the improved compatibility between BF and HDPE matrix after grafting treatments. Original basalt fiber has an inert surface and shows a poor interface adhesion with HDPE resin. However, the compatibility can be significantly improved due to the coupling agent layers between BF and resin matrix after surface modification. On the other hand, there were more effective contact areas on BF surface to disperse stress in the impacting process $[17,19]$.

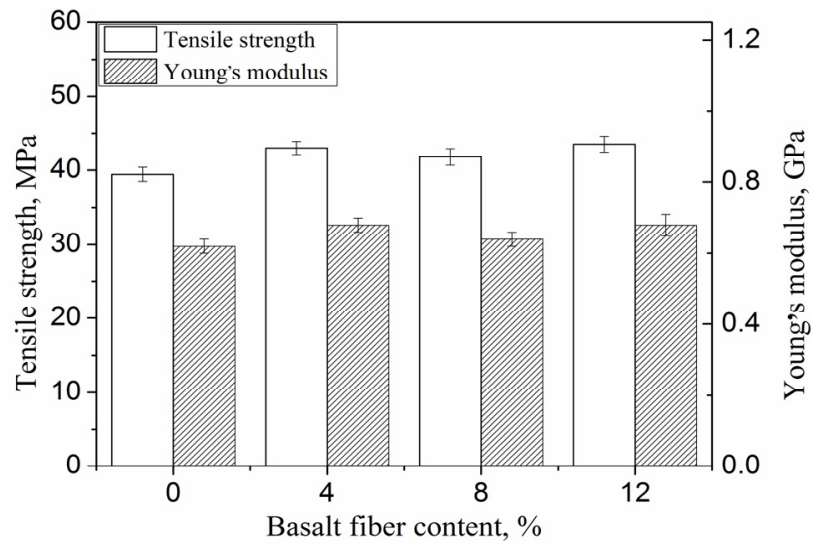

$\mathrm{a}$

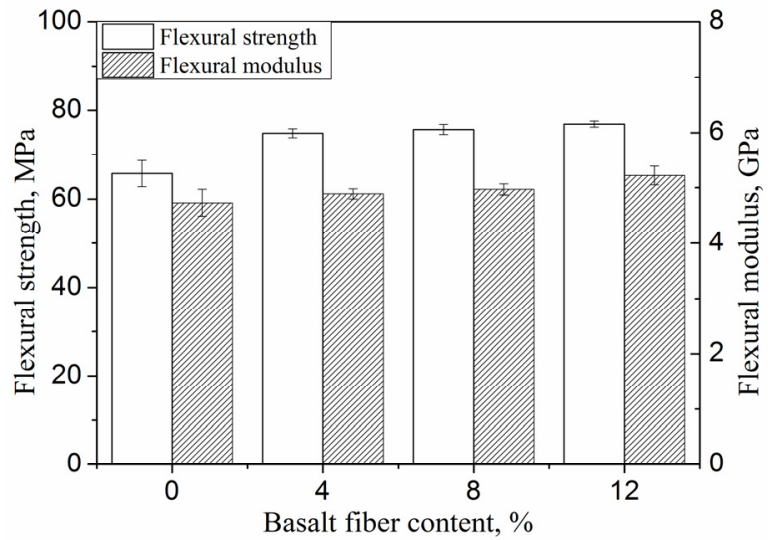

b

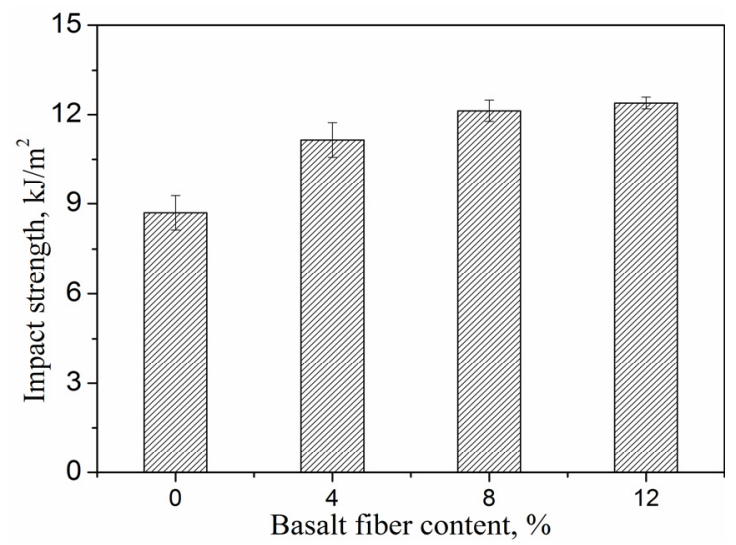

$\mathrm{c}$

Fig. 2. Mechanical properties of YWPC: a - tensile strength and tensile modulus, $\mathrm{b}$ - flexural strength and flexural modulus, $\mathrm{c}$ - impact strength

\subsection{Micrographic analysis of BF and WPCs}

A morphological comparison between the original and modified BF is presented in Fig. 3, a and b. The surface of modified $\mathrm{BF}$ was rougher than that of the original $\mathrm{BF}$ because of the attached chemicals on the BF surface. It is presumed that this rough surface facilitated the interfacial adhesion between the HDPE matrix and BF due to the larger surface area.

In the case of the original BF, its surface is smooth and exhibits a poor interfacial adhesion (Fig. 3, c). On the other hand, the surface treatment produced a rough BF surface, which created a stronger adhesion between the HDPE matrix and the BF surface (Fig. 3,d). These data is consistent with the variation in mechanical properties listed in Fig. 2.

However, BF pullout from matrix could also be observed in Fig. 3, d. It is the dominant failure mode for the YWPC. Because basalt fiber is much stronger with respect to tensile strength than are the wood fiber and resin matrix, basalt fibers were pulled out from the HDPE matrix before breakage. Hence, it is very important to improve the interfacial bonding strength.

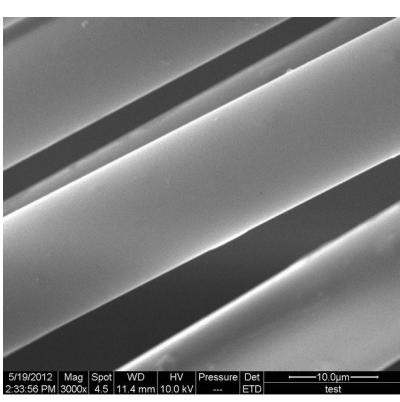

$\mathrm{a}$

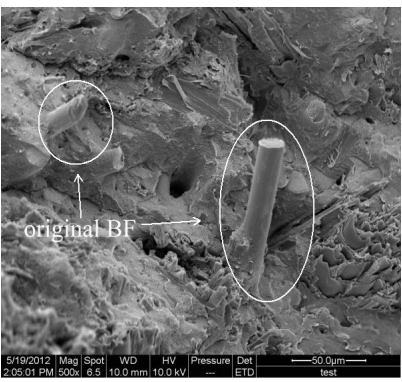

$\mathrm{c}$

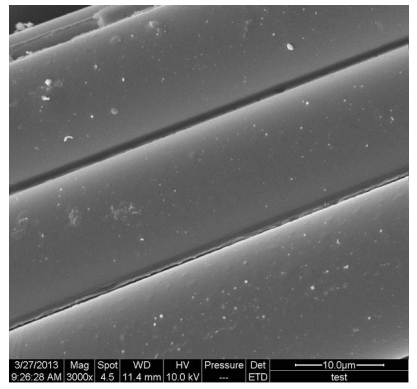

b

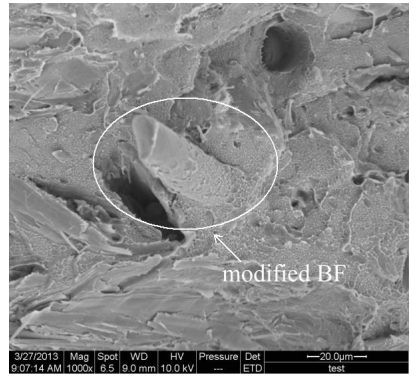

d
Fig. 3. SEM micrographs of $\mathrm{BF}$ and WPCs: a - original $\mathrm{BF}$ $(3000 \times), b-$ modified BF $(3000 \times), c-$ fracture surface of WPC $(1000 \times), d-$ fracture surface of YWPC $(1000 \times)$

\section{CONCLUSIONS}

Basalt fibers modified with a vinyl triethoxy silane coupling agent were introduced into WF/HDPE composites as a reinforcing material. SEM and FT-IR proofed that functional silane can be grafted onto BF and produced rough surfaces. After modification, the surface of the BF became more compatible with the HDPE matrix. Addition of modified BF to wood plastic composites provided better flexural and impact properties. It was proofed that suitable surface treatment is necessary to improve the reinforcement of BF. 


\section{Acknowledgments}

The authors are grateful for the support of the National High-tech R\&D Program of China (863 Program) (2012AA03A204).

\section{REFERENCES}

1. Liu, H., Wu, Q., Han, G., Yao, F., Kojima, Y., Suzuki, S. Compatibilizing and Toughening Bamboo Flour-filled HDPE Composites: Mechanical Properties and Morphologies Composite Part A: Applied Science Manufacture $39(12) \quad$ 2008: pp. 1891-1900.

http://dx.doi.org/10.1016/j.compositesa.2008.09.011

2. Adhikary, K. B., Pang, S. S., Staiger, M. P. Dimensional Stability and Mechanical Behavior of Wood-plastic Composites Based on Recycled and Virgin High-density Polyethylene (HDPE) Composites Part B: Engineering 39 (5) 2008: pp. 807-815. http://dx.doi.org/10.1016/j.compositesb.2007.10.005

3. Ou, R. X., Guo, C. G., Xie, Y. J., Wang, Q. W. Non-isothermal Crystallization Kinetics of Kevlar Fiber-reinforced Wood Flour/HDPE Composites BioResources 6(4) 2011: pp. 4547-4565.

4. Bhuwan, M. P., Mohini, M. S. Mechanical Properties of Thermally Treated Hemp Fibers in Inert Atmosphere for Potential Composite Reinforcement Materials Research Innovations 7 (4) 2003: pp. 231-238.

5. Markarian, J. Wood-plastic Composites: Current Trends in Materials and Processing Plastics Additives and Compounding 7 (5) 2005: pp. 20-26. http://dx.doi.org/10.1016/S1464-391X(05)70453-0

6. Chen, J. X., Wang, Y., Gu, C. L., Liu, J. X. Enhancement of the Mechanical Properties of Basalt Fiber-Wood-Plastic Composites via Maleic Anhydride Grafted High-Density Polyethylene (MAPE) Addition Materials 6 2013: pp. $2483-2496$.

http://dx.doi.org/10.3390/ma6062483

7. Guo, J., Tang, Y. N., Xu, Z. M. Performance and Thermal behavior of Wood Plastic Composite Produced by Nonmetals of Pulverized Waste Printed Circuit Boards Journal of Hazardous Materials 179 (1-3) 2010: pp. $203-207$.

8. Deka, B. K., Maji, T. K. Effect of Coupling Agent and Nanoclay on Properties of HDPE, LDPE, PP, PVC Blend and Phargamites Karka Nanocomposite Composites Science and Technology 70 (12) 2010: pp. 1775-1761.

9. Lai, S. M., Yeh, F. C., Wang, Y., Chan, H. C., Shen, H. F. Comparative Study of Maleated Polyolefins as
Compatibilizers for Polyethylene/Wood-flour Composites Journal of Applied Polymer Science 87 (3) 2003: pp. $487-496$. http://dx.doi.org/10.1002/app.11419

10. Choi, M. H., Jeon, B. H., Chung, I. J. The Effect of Coupling Agent on Electrical and Mechanical Properties of Carbon Fiber/Phenolic Resin Composites Polymer 41 (9) 2000: pp. 3243-3252.

11. Rose, I. M. D., Marra, F., Pulci, G., Santulli, C., Sarasini, F., Tirillo, J., Valente, M. Post-Impact Mechanical Characterisation of Glass and Basalt Woven Fabric Laminates Applied Composites Materials 19 (3-4) 2012: pp. $475-490$

12. Lopresto, V., Leone, C., Iorio, I. D. Mechanical Characterisation of Basalt Fibre Reinforced Plastic Composites Part B: Engineering 42 (4) 2011: pp. 717-723.

13. Militky, J., Kovacic, V., Rubnerova, J. Influence of Thermal Treatment on Tensile Failure of Basalt Fibers Engineering Fracture Mechanics 69 (9) 2002: pp. $1025-1033$.

14. Czigány, T., Vad, J., Pölöskei, K. Basalt Fiber as Reinforcement of Polymer Composites Periodica Polytechnica Series Mechanical Engineering 49 (1) 2005: pp. 3-14.

15. Öztürk, S. The Effect of Fibre Content on the Mechanical Properties of Hemp and Basalt Fibre Reinforced Phenol Formaldehyde Composites Journal of Materials Science 40 (17) 2005: pp. 4585-4592.

16. Mingchao, W., Zuoguang, Z., Yubin, L., Min, L., Zhijie, S. Chemical Durability and Mechanical Properties of Alkali-proof Basalt Fiber and Its Reinforced Epoxy Composites Journal of Reinforced Plastics and Composites 27 (4) 2008: pp. 393-407.

17. Chen, J. X., Guan, S. J., Zhang, S. H., Zheng, J. J., Xie, J., Lu, Y. Development of Basalt Fiber Reinforced Wood-plastic Composite Advanced Materials Research 189-193 2011: pp. 4043-4048.

18. Hatsuo, I., Jack, L. K. Fourier Transform Infrared Spectroscopic Study of the Silane Coupling Agent/Porous Silica Interface Journal of Colloid Interface Science 64 (3) 1978: pp. 555-564. http://dx.doi.org/10.1016/0021-9797(78)90398-3

19. Ou, R. X., Zhao, H., Sui, S. J., Song, Y. M., Wang, Q. W. Reinforcing Effects of Kevlar Fiber on The Mechanical Properties of Wood-flour/ High-density-polyethylene Composites Composites Part A: Applied Science and Manufacturing 41 (9) 2010: pp. 1272-1278. http://dx.doi.org/10.1016/j.compositesa.2010.05.011 